\title{
中国石生针茅草原的分布、群落特征和分类
}

\author{
乔鲜果 ${ }^{1,2}$ 郭 柯 ${ }^{1,2 *}$ 赵利清 ${ }^{3}$ 刘长成 ${ }^{1}$ 赵海卫 $^{1,2}$ 侯东杰 $^{1,2}$ 高趁光 ${ }^{1,2}$ \\ ${ }^{1}$ 中国科学院植物研究所植被与环境变化国家重点实验室, 北京 $100093 ;{ }^{2}$ 中国科学院大学, 北京 $100049 ;{ }^{3}$ 内蒙古大学生命科学学院, 呼和浩特 \\ 010021
}

摘 要 石生针茅(Stipa tianschanica var. klemenzii)草原是中国荒漠草原最具代表性的植被类型。该文利用2010-2016年生长 季的野外调查数据并结合已有文献资料, 对中国石生针茅草原的生态地理分布、群落学特征以及类型划分进行了全面系统的 分析。结果表明: 中国石生针茅草原主要分布在内蒙古锡林郭勒高原西部和乌兰察布高原, 常分布在棕钻土基质的高平原上; 分布区气候干旱, 群落高度、盖度、生物量和物种丰富度较低; 根据80个样地的数据统计, 石生针茅草原共记录到种子植物 165 种, 隶属于 29 科 85 属, 其中以偶见种(存在度 $<20 \%$ )居多, 占 $87 \%$, 常见种和恒有种较少, 存在度大于 $50 \%$ 的物种有石生针 茅、银灰旋花(Convolvulus ammannii)、无芒隐子草(Cleistogenes songorica)、细叶非(Allium tenuissimum); 物种生活型以地面 芽植物和一年生植物居多, 分别占 $55 \%$ 和 $20 \%$; 水分生态类型以典型旱生植物居多, 占 $47 \%$, 其次为强旱生植物和中旱生植 物; 区系地理成分以亚洲中部和东古北极成分为多, 分别占 $37 \%$ 和 $26 \%$; 根据生活型和物种的优势度, 石生针茅群系可划分 为6个群丛组、29个群丛。

关键词 丛生禾草草原; 生活型谱; 区系地理成分; 群落分类

引用格式: 乔鲜果, 郭柯, 赵利清, 刘长成, 赵海卫, 侯东杰, 高趁光 (2017). 中国石生针茅草原的分布、群落特征和分类. 植物生态学报, 41, $231-237$. doi: 10.17521/cjpe.2016.0053

\section{Distribution, community characteristics and classification of Stipa tianschanica var. klemenzii steppe in China}

QIAO Xian-Guo ${ }^{1,2}$, GUO Ke ${ }^{1,2^{*}}$, ZHAO Li-Qing ${ }^{3}$, LIU Chang-Cheng ${ }^{1}$, ZHAO Hai-Wei ${ }^{1,2}$, HOU Dong-Jie ${ }^{1,2}$, and GAO Chen-Guang ${ }^{1,2}$

${ }^{1}$ State Key Laboratory of Vegetation and Environmental Change, Institute of Botany, Chinese Academy of Sciences, Beijing 100093, China; ${ }^{2}$ University of Chinese Academy of Sciences, Beijing 100049, China; and ${ }^{3}$ College of Life Science, Inner Mongolia University, Hohhot 010021, China

\begin{abstract}
Stipa tianschanica var. klemenzii steppe is the most typical formation of desert steppe in China. Based on the primary plots data obtained from fieldworks during the growing seasons from 2010 to 2016 as well as some earlier records, we studied the Stipa tianschanica var. klemenzii steppe across China systematically, including the eco-geographical distributions, community characteristics and classifications. The results showed that S. tianschanica var. klemenzii steppe distributed mainly on the Ulan Qab Plateau and western Xilin Gol Plateau. Due to the arid biotope of $S$. tianschanica var. klemenzii steppe, quantitative characteristics of the assemblage including height, coverage, biomass and species richness were normally lower than that of most Stipa formations in Eurasian steppe region. Moreover, 165 seed plants belonging to 85 genera and 29 families were recorded in the 80 study sites, in which rare species (occurrence frequency $<20 \%$ ) made up $87 \%$ of the total plants while common species and constant species could only be found occasionally. Species with the occurrence frequency exceeding $50 \%$ included S. tianschanica var. klemenzii, Convolvulus ammannii, Cleistogenes songorica, Allium tenuissimum. In addition, Hemicryptophyte and therophyte were the two dominant life forms, covering $55 \%$ and $20 \%$ of the species, respectively. As for the ecological type of water, typical xerophytes accounted for $47 \%$ of all species which is followed by super-xerophytes and meso-xerophytes. Middle Asian areal-type and east Palaeo-North areal-type were the two major floristic elements, containing $37 \%$ and $26 \%$ of the species, respectively. Based on the life forms and dominances of the species within the community, S. tianschanica var. klemenzii steppe in China could be classified into 6 association groups, 29 associations.
\end{abstract}

Key words bunch grass steppe; life-form spectrum; floristic geographic elements; community classification

Citation: Qiao XG, Guo K, Zhao LQ, Liu CC, Zhao HW, Hou DJ, Gao CG (2017). Distribution, community characteristics and classification of Stipa tianschanica var. klemenzii steppe in China. Chinese Journal of Plant Ecology, 41, 231-237. doi: 10.17521/ cjpe.2016.0053 
石生针茅(也叫小针茅)(Stipa tianschanica var. klemenzii)草原是以石生针茅为建群种形成的植被 类型, 是亚洲中部荒漠草原地带的一类小型从生禾 草草原, 是最耐干旱的一种针茅草原, 在我国主要 分布在乌兰察布高平原和鄂尔多斯高原中西部地 区，往西在荒漠区的山地(贺兰山、祁连山、柴达木、 阿尔泰山、东天山等)也有出现(中国植被编辑委员 会, 1980)。

石生针茅和戈壁针茅(Stipa tianschanica var. gobica)形态特征相似, 两者的区别主要表现在: 1) 石生针茅基生叶叶舌长1.0-1.5 mm, 先端具不足1 $\mathrm{mm}$ 的纤毛, 叶鞘光滑, 戈壁针茅基生叶叶舌长约1 $\mathrm{mm}$, 先端具明显长于叶舌片的柔毛, 叶鞘粗糙; 2) 石生针茅外稃长约 $10 \mathrm{~mm}$ (变化在9-11 mm之间), 戈壁针茅外稃长7-9 mm; 3)石生针茅干燥的芒常呈 镰状弯曲, 戈壁针茅干燥的芒呈直角弯曲。在《中 国植物志》(2004)和《Flora of China》(2013)中, 仅 以颖片和芒针的长短来区分, 在植被调查时极易辨 认错误。另外, 两者在分布和生态适应特征上区别 也很大, 石生针茅草原主要生长在典型的棕钻土上, 是蒙古高原荒漠草原最具代表性的群落类型, 而戈 壁针茅草原生于荒漠草原带及典型草原带西部的石 质山地与丘陵, 一般只形成小面积的群落(内蒙古 植物志编辑委员会, 1998; 陈灵芝等, 2014)。在《内 蒙古植被》(1985)中写到“戈壁针茅外稃长10 mm, 芒一次膝曲, 呈弯镰状”, 但这是属于石生针茅的形 态特征。另外, 《中国植被》(1980)、《内蒙古植被》 (1985)以及《中华人民共和国植被图1:1000 000》 (2007)中说到戈壁针茅是内蒙古高原荒漠草原地区 地带性植被的建群种, 是棕钙土上的典型代表植物, 而石生针茅主要见于山地和丘陵上部, 并与砾石质 粗骨土壤有密切关系, 这与前面所述内容相悖。我 们在2010-2016年生长季调查了80个石生针茅的样 地和67个戈壁针茅的样地, 确认了两者在生境与生 态适应性方面的差异。综上所述, 我们认为《中国 植被》(1980)、《内蒙古植被》(1985)以及《中华人 民共和国植被图1:1000 000》(2007)中所描述的戈壁 针茅草原应是石生针茅草原的生态特征, 而石生针 茅草原的相关描述是戈壁针茅草原的内容。

植被调查的样方资料是定性或定量描述群落特 征的重要依据, 也是植被类专著编研的主要资料来 源(杨瑶等, 2014)。因此植物群落的详尽调查是研究
一个地区植被特征的重要基础, 更是当今科学研究 的需求。石生针茅草原现有文献所利用数据多是 20 世纪80年代以前的, 侧重定性的描述, 缺乏详细的 样方数据和定量化的指标, 群系下未进行过系统分 类(中国植被编辑委员会, 1980; 中国科学院内蒙古 宁夏综合考察队, 1985)。本文基于2010-2016年生长 季野外调查的 80 个样地数据对中国石生针茅草原的 生态地理分布、群落特征及类型划分进行相对全面 的总结, 以期为 《中国植被志》的编研提供基础数 据和资料。

\section{1 研究方法}

\section{1 样地及样方调查}

野外考察于2010-2016年生长季展开。考查范围 从内蒙古新巴尔虎旗的克鲁伦河南岸向西南方向延 伸至青海省以及西藏阿里地区，包括呼伦贝尔高 原、锡林郭勒高原、乌兰察布高原、鄂尔多斯高原、 黄土高原、荒漠区山地(贺兰山、祁连山、阿尔泰山、 天山)和青藏高原。

野外考察采用样地和样方双层调查。样地调查 是对一个地区植被全面勘察后, 选取 $20 \mathrm{~m} \times 50 \mathrm{~m}$ 的 典型群落地段, 对这个样地作一般性描述和物种数 量特征记录，一般性描述包括样地编号、面积、日 期、植物群落名称、地理位置、海拔高度、地貌、 生境信息、干扰情况等, 物种数量特征是样地内的 所有物种的高度和盖度信息, 并形成样地调查表 (见附录)。

样方调查是在典型地段选取 $3-5$ 个 $1 \mathrm{~m} \times 1 \mathrm{~m}$ 的 小样方进行, 首先是样方描述, 包括样方编号、面 积、生境、干扰等信息; 其次对样方内的所有物种 展开调查, 包括群落高度、盖度、物种高度、分盖 度、密度, 采用收获法获得地上生物量。样方调查 数据以样方调查表形式保存(见附录)。

\section{2 数据处理及分析}

根据样地调查表和样方调查表的数据对石生针 茅草原的群落学特征进行分析。首先对石生针茅草 原中出现的所有物种进行名录整理, 确定其科属组 成、生活型、水分生态类型和区系地理成分。然后 对群落的物种丰富度、Shannon-Wiener多样性指数 $\left(H^{\prime}\right)$ 、Pielou均匀度指数 $(J)$ 、物种重要值 $(I V)$ 进行分 析计算, 公式如下: $H^{\prime}=\sum P_{i} \log _{2} P_{i}, J=H^{\prime} / H_{\text {max }}^{\prime}$, $H_{\text {max }}^{\prime}=\ln S$ 。式中: $S$ 为群落中的物种数, $P_{i}$ 为物种 $i$ 的 
重要值在全部植物重要值中的比例, $H_{\text {max }}^{\prime}$ 是最大均 匀条件下的群落多样性指数。物种重要值的计算采 用公式 $I V=($ 相对盖度 + 相对高度 + 相对生物量 $) / 3$, 在盖度缺失的样地中, 采用公式 $I V=($ 相对高度 + 相 对生物量)/2计算; 最后以建群种和次优势层/次优 势层片优势物种命名群丛组和群从(陈灵芝等, 2014)。

样地的气象数据根据国家气象中心提供的全国 731个气象站点1980-2010年的逐月气象数据, 利用 ArcGis软件插值计算得到。数据的统计和分析利用 SPSS 17.0和Excel软件进行。

\section{2 结果和分析}

\section{1 石生针茅草原的分布与生态特征}

在地理分布上, 已有资料记载石生针茅仅在内 蒙古有分布(中国植物志编辑委员会, 2004; Wu et al., 2013), 调查中发现在陕西、宁夏、甘肃、青海、 新疆和西藏均有石生针茅的分布。石生针茅草原在 我国集中分布于阴山山脉以北的锡林郭勒高原西部 和乌兰察布高原, 往南在鄂尔多斯高原的西部地区 也有广泛的分布, 并可延伸至宁夏同心县、盐池县、 海原县、中卫县以及陕西靖边县等, 往东在内蒙古 东乌珠穆沁旗以及新巴尔虎旗的克鲁伦河南岸也有 分布, 往西在甘肃省祁连山东段低山区、青海省的 共和县、德令哈市西南方向、新疆东天山山前冲积 平原和低山丘陵区以及西藏阿里地区革吉县文布当 桑乡也有记录。集中分布区呈带状, 介于典型草原 区和荒漠区之间, 形成大面积的荒漠草原景观。与 原分布区相比, 新增加了呼伦贝尔高原和青藏高原 分布区。另外, 在锡林郭勒高原, 其分布东界从苏尼 特左旗和苏尼特右旗的部分地区扩展到苏尼特左旗 和右旗的大部分地区, 而且在阿巴嘎旗、镶黄旗和 东乌珠穆沁旗也有相当面积的分布。

对 80 个样地的环境特征统计显示, 石生针茅草 原广泛分布在高平原的棕钻土基质上, 在荒漠区常 分布在石质化严重的山麓, 地面粗糖, 常覆盖有细 小石砾和粗砂, 土体腐殖层较薄, 钙积层常分布在 地下 20-30 cm土层。分布区的海拔高度平均为 1455 $\mathrm{m}$, 最高出现在西藏文布当桑乡4601 m, 最低出现 在内蒙古新巴尔虎旗588 m, 分布区的海拔高度表 现出自东向西、自北向南显著升高, 从锡林郭勒高 原的850-1 $160 \mathrm{~m}$ 、乌兰察布高原的1200-1600 m到
宁夏地区的1700-2000 m, 在荒漠区山地海拔达 2000-4 $000 \mathrm{~m}$ 。年总辐射量平均为 $1.28 \times 10^{5} \mathrm{~W} \cdot \mathrm{m}^{-2}$, 年降水量平均为 $241 \mathrm{~mm}$, 最低 $167 \mathrm{~mm}$, 最高 304 $\mathrm{mm}$, 反映了分布区的干旱特征。年平均气温为 5.0 ${ }^{\circ} \mathrm{C}$, 最低 $0.3{ }^{\circ} \mathrm{C}$, 最高 $8.45{ }^{\circ} \mathrm{C}$; 最冷月平均气温为 $-1.0{ }^{\circ} \mathrm{C}$; 最暖月平均气温为 $11.8{ }^{\circ} \mathrm{C}$; $\geqslant 10{ }^{\circ} \mathrm{C}$ 积温 为2 000-3 $100{ }^{\circ} \mathrm{C}$ 。植物生长期一般为6-7个月, 期 间往往发生较长时间的干旱胁迫。

\section{2 石生针茅草原的群落特征}

\subsection{1 群落数量特征及结构特征}

群落的数量特征是针对群落整体进行的定量化 描述, 包括群落高度、盖度、生物量、物种丰富度 等。石生针茅草原作为荒漠草原的典型类型, 在数 量特征上较低。根据 80 个样地的统计, 群落平均高 度 $14 \mathrm{~cm}$, 最低 $5 \mathrm{~cm}$, 最高 $24 \mathrm{~cm}$, 草层较矮; 群落平 均盖度 $19 \%$, 最小 $11 \%$, 最大 $34 \%$, 覆盖度低; 平均 鲜物质生产量为 $101 \mathrm{~g} \cdot \mathrm{m}^{-2}$, 最小 $18 \mathrm{~g} \cdot \mathrm{m}^{-2}$, 最大 325 $\mathrm{g} \cdot \mathrm{m}^{-2}$, 受干扰强度、当年降水量和降水分配影响较 大; 平均干物质生产量为 $60 \mathrm{~g} \cdot \mathrm{m}^{-2}$, 最小 $11 \mathrm{~g} \cdot \mathrm{m}^{-2}$, 最大 $150 \mathrm{~g} \cdot \mathrm{m}^{-2}$; 物种平均丰富度为 8.5 个 $\cdot \mathrm{m}^{-2}$, Shannon-Wiener指数为 $2.38 \pm 0.30$, Pielou均匀度指 数为 $0.97 \pm 0.04$ 。

石生针茅群落的垂直结构简单, 通常分为3层。 第一层是灌木和半灌木, 高 40-50 cm, 主要有红砂 (Reaumuria songarica)、珍珠猪毛菜(Salsola passerina)、松叶猪毛菜(Salsola laricifolia)等镶嵌于群 落中; 中间层是草本层, 由石生针茅、短花针茅 (Stipa breviflora)等丛生禾草以及一些杂类草组成, 高20-30 cm; 下层由冷蒿(Artemisia frigida)、女蒿 (Hippolytia trifida)、燥原荠(Ptilotricum canescens) 等小半灌木以及九顶草(Enneapogon desvauxii)、乳 白花黄耆 (Astragalus galactites)、银灰旋花 (Convolvulus ammannii)、教藜(Tribulus terrestris)等 低矮杂类草和禾草组成, 高5-10 cm。

\subsection{2 物种组成}

80 个样地共记录到种子植物 165 种, 隶属于 29 科85属。其中单子叶植物 4 科 24 属 48 种, 双子叶植物 25科61属117种。物种较多的科依次是禾本科(18属 30 种)、菊科(16属29种)、豆科(6属25种)、僽科(8属 15 种)、百合科(3属10种), 其次为蓄薇科、石竹科、 莎草科、十字花科、鸢尾科、报春花科、麻黄科、 教藜科、柽柳科、骆驼蓬科、陇牛儿苗科、亚麻科、 
旋花科、紫草科、唇形科, 剩下的 9 科各含 1 个物种。 含种数较多的属有黄耆属(Astragalus, 10种), 蒿属 (Artemisia，8种), 棘豆属(Oxytropis, 7种), 䓤属 (Allium, 6种), 委陵菜属(Potentilla, 6种), 猪毛菜属 (Salsola，5种), 鸦苾属(Scorzonera，5种), 针茅属(5 种), 其中 52 个属只含 1 个种。

根据165种植物在 80 个样地中出现的百分比可 将其划分为 5 个存在度等级(图1)。其中存在度 I级 (0-20\%)的物种占 $87 \%$, 是群落中的偶见种, 有中亚 细柄茅 (Ptilagrostis pelliotii)、硬阿魏 (Ferula bungeana)、西北风毛菊(Saussurea petrovii)、紊蒿 (Elachanthemum intricatum)、镰荚黄耆(Astragalus arpilobus)等; II级 $(20 \%-40 \%)$ 物种主要是群落的伴 生种, 有猪毛菜(Salsola collina)、九顶草、冰草 (Agropyron cristatum)、阿尔泰狗娃花(Heteropappus altaicus)、蒙古非 (Allium mongolicum) 等; III 级 (40\%-60\%)物种是群落的常见种, 有无芒隐子草 (Cleistogenes songorica)、细叶韭 (Allium tenuissimum)、糙隐子草(Cleistogenes squarrosa)、碱非 (Allium polyrhizum)、乳白花黄耆; IV级(60\%-80\%) 只有银灰旋花1种, 是常见的次优势种或恒有种; $\mathrm{V}$ 级(80\%-100\%)物种只有石生针茅, 是建群种。

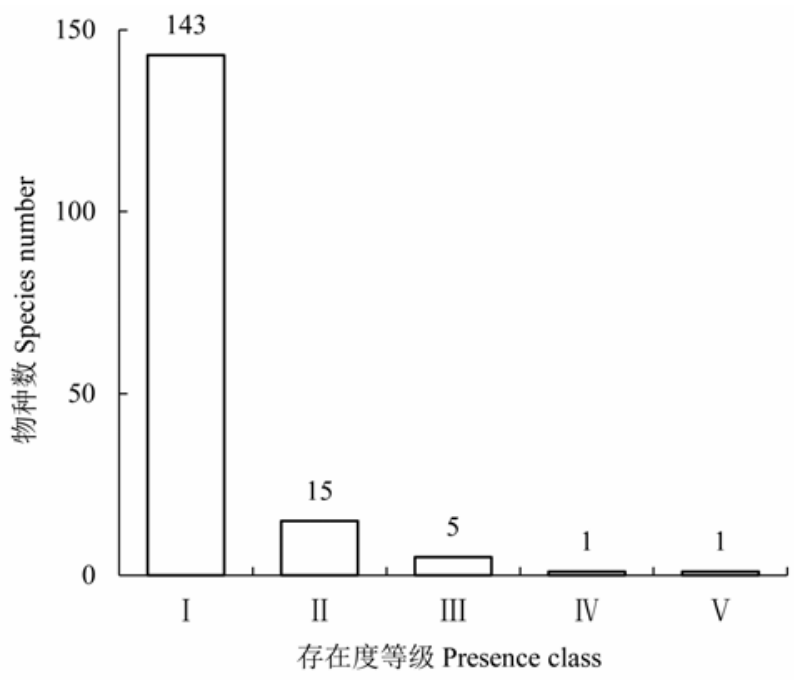

图1 石生针茅草原物种的存在度等级分布。I, 0-20\%; II, 20\%-40\%; III, 40\%-60\%; IV, 60\%-80\%; V, 80\%-100\%。

Fig. 1 The frequency distribution of species with different presence classes in Stipa tianschanica var. klemenzii steppe. I, 0-20\%; II, 20\%-40\%; III, 40\%-60\%; IV, 60\%-80\%; V, $80 \%-100 \%$.

\subsection{3 生活型及水分生态类型}

根据Raunkiaer的生活型系统可将石生针茅草
原的 165 种植物划分为4类生活型, 形成生活型谱 (图2)。地面芽植物作为草原植被的优势生活型，也 是石生针茅草原的优势类群，占55\%，包括多年生 丛生禾草18种和多年生杂类草73种; 一年生植物以 种子越冬, 处于次优势地位, 反映了分布区常年干 旱、冬春严寒的特点, 占 $20 \%$, 主要是一年生杂类草 和一年生禾草组成, 以僽科、禾本科、菊科居多; 地 上芽植物占 $14 \%$, 由小灌木和小半灌木组成, 主要 是由兴安胡枝子(Lespedeza daurica)、燥原荠、红砂、 珍珠猪毛菜、猫头刺(Oxytropis aciphylla)等强旱生 和旱生物种组成; 隐芽植物最少, 占 $10 \%$, 主要是 禾本科根茎类禾草、百合科鳞茎植物、莎草科根茎 薹草和嵩草。

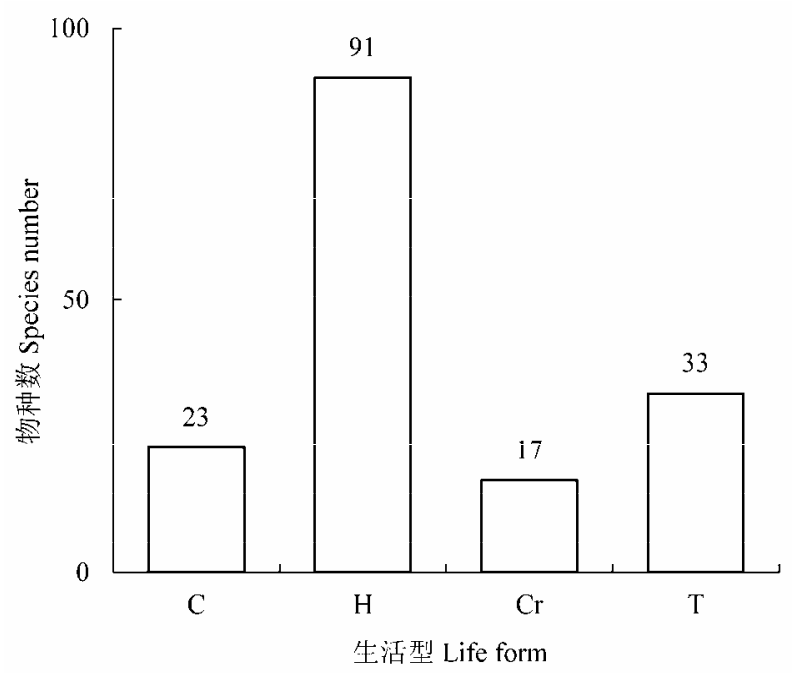

图2 石生针茅草原物种的生活型谱。C, 地上芽植物; $\mathrm{H}$, 地面芽植物; $\mathrm{Cr}$, 隐芽植物; $\mathrm{T}$, 一年生植物。

Fig. 2 The frequency distribution of the species with different life-forms in Stipa tianschanica var. klemenzii steppe. C, chamaephytes; H, hemicryptophytes; $\mathrm{Cr}$, cryptophytes; T, therophytes.

根据植物对水分因子的适应特征可将其划分为 不同的水分生态类群。通过查阅相关资料, 可将石 生针茅草原的 165 种植物划分为 7 种水分生态类型 (图3)。典型旱生类型居多，常见的有石生针茅、西 北针茅(Stipa sareptana var. krylovii)、冰草、乳白花 黄耆、蒙古非等共78种，占47\%，其次为强旱生和中 旱生类型, 强旱生类型有红砂、猫头刺、珍珠猪毛 菜、荒漠锦鸡儿(Caragana roborovskyi)、革苞菊 (Tugarinovia mongolica)、米蒿(Artemisia dalai-lamae)、 碱韭、白茎绢蒿(Seriphidium terrae-albae)等, 中旱 生类型包括兴安天门冬(Asparagus dauricus)、野非

www.plant-ecology.com 


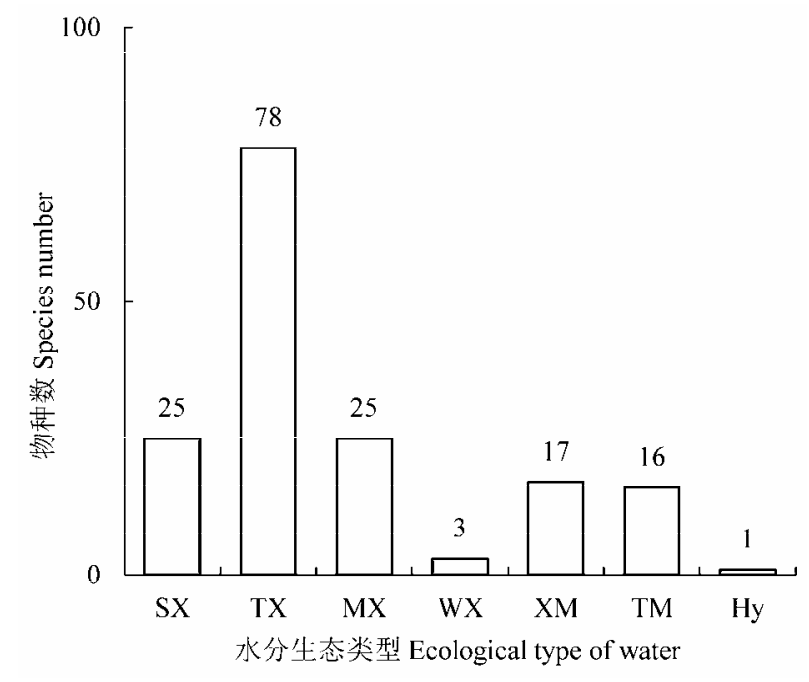

图3 石生针茅草原物种的水分生态类型谱。SX, 强早生植 物; TX, 典型旱生植物; MX, 中旱生植物; WX, 广旱生植 物; XM, 旱中生植物; TM, 典型中生植物; Hy, 湿生植物。

Fig. 3 The frequency distribution of the species with different ecological types of water in Stipa tianschanica var. klemenzii steppe. SX, super-xerophytes; TX, typical xerophytes; MX, meso-xerophytes; WX, wild xerophytes; XM, xero-mesophytes; TM, typical mesophytes; Hy, hygrophytes.

(Allium ramosum)、兴安胡枝子、阿尔泰狗娃花等。

\subsection{4 物种区系地理成分}

通过查阅相关资料以及对分布区的分析, 确定 石生针茅草原的植物区系地理成分, 属于10类(图 4)。亚洲中部成分最多, 占37\%, 有石生针茅、无芒 隐子草、西北针茅、蒙古非、碱非、冬青叶兔唇花 (Lagochilus ilicifolius)等; 东古北极成分次之, 占 $26 \%$, 有银灰旋花、细叶苾、兴安天门冬、砂非 (Allium bidentatum)、细叶㫭尾(Iris tenuifolia)等; 东 亚成分占 $8 \%$, 泛北极成分占 $7 \%$, 古地中海成分占 $6 \%$, 古北极成分占 $5 \%$, 中亚-亚洲中部成分占 $5 \%$, 世界分布和泛温带成分各占 $2 \%$; 青藏臺草(Carex moorcroftii)、固沙草(Orinus thoroldii)和木根香青 (Anaphalis xylorhiza)作为青藏高原成分占 $2 \%$ 。区系 成分的多样化反映了物种广泛传播和渗透性。

\section{3 石生针茅群系分类}

依照《中国植物区系和植被地理》(2014)中的 植被分类原则和系统、植物群落命名原则对石生针 茅草原进行分类和命名。根据生活型层片及物种优 势度将石生针茅群系划分为 6 个群丛组、29个群丛 (表1)。6个群从组的主要特征如下: 1)石生针茅、小 灌木/小半灌木群丛组是荒漠化程度最高的类型, 年降水量不足 $200 \mathrm{~mm}$ 。作为次优势种的红砂、萻状
亚菊、珍珠猪毛菜、蒿叶猪毛菜(Salsola abrotanoides) 和猫头刺都是耐旱性极强的类群, 因此所属的群丛 分布在荒漠草原区和荒漠区交接的地带(内蒙古巴 彦淖尔盟乌拉特中旗、阿拉善左旗以及宁夏中卫 市), 也可出现在干旱的湖滨阶地 (青海共和县切吉 乡)。白莲蒿是广幅旱生植物, 石生针茅与白莲蒿形 成的群落分布在内蒙古锡林郭勒盟的苏尼特右旗。

2)若群落中缺乏明显的亚优势层片或亚优势种, 则 形成单优群从组或群丛, 一共 22 个样地。该类型分 布范围广泛, 在锡林郭勒盟的东乌珠穆沁旗、二连 浩特、乌拉特中旗、乌拉特后期、宁夏中南部、陕 西西部地区以及新疆哈密地区都有分布。是代表性 的群落类型, 年降水量 $280 \mathrm{~mm}$ 。3)其他丛生禾草如 西北针茅、短花针茅等作为优势层片的次优势种可 形成石生针茅、丛生禾草群丛组和相应的群丛, 记 录到15个样地。石生针茅+西北针茅群丛分布在水 分相对较好的区域, 年降水量达到 $300 \mathrm{~mm}$, 在呼伦 贝尔盟的克鲁伦河、阿巴嘎旗以及乌拉特中旗有分 布。4)具有长根茎的沙鞭(Psammochloa villosa)和固 沙草分别是蒙古高原和青藏高原的沙生先锋植物, 在沙质化的基质上常占据优势地位, 可与建群种形

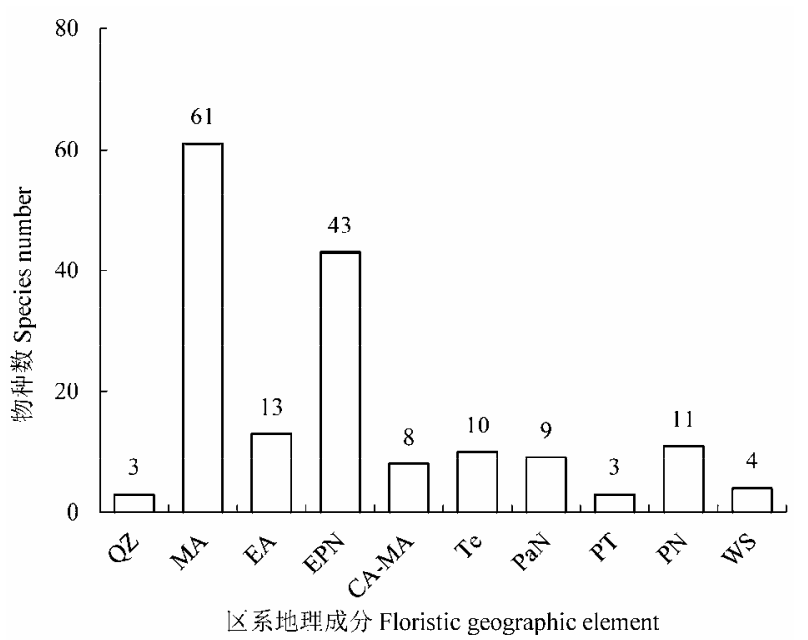

图4 石生针茅草原物种的区系地理成分组成。QZ, 青藏高 原特有成分; MA, 亚洲中部成分; EA, 东亚成分; EPN, 东 古北极成分; CA-MA, 中亚-亚洲中部成分; Te, 古地中海 成分; PaN, 古北极成分; PT, 泛温带成分; PN, 泛北极成 分; WS, 世界广布种。

Fig. 4 The frequency distribution of the species with different floristic elements in Stipa tianschanica var. klemenzii. QZ, Qinghai-Xizang Plateau element; MA, middle Asia element; EA, east Asia element; EPN, east Palaeo-North element; CA-MA, central Asia-middle Asia element; Te, Tethys element; PaN, Palaeo-North element; PT, Pan-Temeperate element; PN, Pan-North element; WS, wide spread element. 
表1 石生针茅草原群系分类

Table 1 The classification of Stipa tianschanica var. klemenzii steppe at the formation level

\begin{tabular}{lll}
\hline 群丛组 Association group & 群丛 Association & 样地编号 Plot number \\
\hline 石生针茅、小灌木/小半灌木 & 石生针茅-蒿叶猪毛菜 Stipa tianschanica var. klemenzii-Salsola abrotanoides & P1 \\
Stipa tianschanica var. klemenzii, & 石生针茅-白莲蒿 Stipa tianschanica var. klemenzii-Artemisia sacrorum & P40 \\
dwarf shrubs/dwarf subshurbs & 石生针茅-红砂 Stipa tianschanica var. klemenzii-Reaumuria songarica & P54, P60 \\
& 石生针茅-珍珠猪毛菜 Stipa tianschanica var. klemenzii-Salsola passerine & P57, P66 \\
& 石生针茅猫头刺 Stipa tianschanica var. klemenzii-Oxytropis aciphylla & P62 \\
& P63 石生针茅-女高 Stipa tianschanica var. klemenzii-Hippolytia trifida & P71 \\
& 石生针茅-蓄状亚菊 Stipa tianschanica var. klemenzii-Ajania achilleoides &
\end{tabular}

石生针茅

Stipa tianschanica var. klemenzii

石生针茅、丛生禾草

Stipa tianschanica var. klemenzii, bunchgrasses

石生针茅、根茎禾草

Stipa tianschanica var. klemenzii, rhizomatous grasses

石生针茅、杂类草

Stipa tianschanica var. klemenzii, forbs
石生针茅 Stipa tianschanica var. klemenzii

石生针茅+冰草 Stipa tianschanica var. klemenzii + Agropyron cristatum 石生针茅+精隐子草 Stipa tianschanica var. klemenzii + Cleistogenes squarrosa 石生针茅+西北针茅 Stipa tianschanica var. klemenzii + Stipa sareptana var. krylovii 石生针茅+短花针茅 Stipa tianschanica var. klemenzii + Stipa breviflora 石生针茅+无芒隐子草 Stipa tianschanica var. klemenzii + Cleistogenes songorica

石生针茅+沙鞭 Stipa tianschanica var. klemenzii + Psammochloa villosa 石生针茅+固沙草 Stipa tianschanica var. klemenzii + Orinus thoroldii 石生针茅+沙芦草 Stipa tianschanica var. klemenzii + Agropyron mongolicum

石生针茅+碱非 Stipa tianschanica var. klemenzii + Allium polyrhizum

石生针茅+草芸香 Stipa tianschanica var. klemenzii + Haplophyllum dauricum 石生针茅+兴安天门冬 Stipa tianschanica var. klemenzii + Asparagus dauricus 石生针茅+银灰旋花 Stipa tianschanica var. klemenzii + Convolvulus ammannii 石生针茅+细叶㚜尾 Stipa tianschanica var. klemenzii + Iris tenuifolia 石生针茅+砂非 Stipa tianschanica var. klemenzii + Allium bidentatum 石生针茅+骆驼蓬 Stipa tianschanica var. klemenzii + Peganum harmala 石生针茅+西北风毛菊 Stipa tianschanica var. klemenzii + Saussurea petrovii 石生针茅+细叶石头花 Stipa tianschanica var. klemenzii + Gypsophila licentiana 石生针茅+短翼岩黄耆 Stipa tianschanica var. klemenzii + Hedysarum brachypterum 石生针茅+白茎绢蒿 Stipa tianschanica var. klemenzii + Seriphidium terrae-albae

石生针茅+九顶草 Stipa tianschanica var. klemenzii + Enneapogon desvauxii 石生针茅+猪毛菜 Stipa tianschanica var. klemenzii + Salsola collina
P6, P7, P8, P10, P11, P13, P14, P15, P16, P17, P23, P28, P36, P50, P52, P65, P67, P68, P69, P72, P75, P79

P2, P20

$\mathrm{P} 3, \mathrm{P} 4$

P5, P33, P35, P51

$\mathrm{P} 21, \mathrm{P} 22, \mathrm{P} 24$

P30, P31, P49, P61

P38

P76

P77

P18, P32, P34, P43, P45, P56, P58, P64

P27

P29

P41, P42, P47, P80

P53

P55

P59

P70

P73

P74

P78

P9, P12, P19, P25, P26, P46, P48

P37, P39, P44

Stipa tianschanica var. klemenzii, annual grasses

石生针茅猪毛莱 Stipa tianschanica var. klemenzil + Salsola collina

成石生针茅+沙鞭群从(内蒙古苏尼特右旗)和石生 针茅+固沙草群从(西藏革吉县文布当桑乡); 在祁 连山东段沙质化的山坡上分布有石生针茅+沙芦草 (Agropyron mongolicum)群丛。5)当亚优势层片是多 年生杂类草时便形成石生针茅、杂类草群丛组, 共 记录到11个群丛类型、21个样地。石生针茅+碱非 是代表性的群落, 旱生性强, 主要分布在乌兰察布 高原的沙质棕钙土上; 石生针茅+骆驼蓬(Peganum harmala) 和石生针茅+银灰旋花群从是在放牧压力 下形成的轻度退化类型, 以适口性差的骆驼蓬和银 灰旋花占次优势地位, 主要分布在巴彦淖尔盟的乌 拉特中旗和锡林郭勒盟西部。6)一年生植物层片作 为荒漠草原的重要组成部分, 在多雨年份发育极好,
其盖度、密度及生物量有时仅次于甚至超过建群种 形成石生针茅、一年生植物群从组, 分布在内蒙古 高原的乌拉特中旗和苏尼特右旗。

\section{3 结论和讨论}

1)石生针茅草原在我国集中分布在锡林郭勒高 原西部和乌兰察布高原, 在呼伦贝尔高原和青藏高 原为首次记录该类型。与《中国植被》(1980)和《中 华人民共和国植被图1:1000 000》(2007)记载的分布 区相比, 分布范围和分布面积都有较大的增加。石 生针茅草原一般分布在棕钙土基质的高平原上, 土 壤在20-30 cm处普遍存在钻积层。分布区温暖、干 燥, 海拔1 $500 \mathrm{~m}$ 左右, 年降水量 $250 \mathrm{~mm}$ 左右, 年平

www.plant-ecology.com 
均气温 $5{ }^{\circ} \mathrm{C}$ 。另外, 据《中国植被》(1980)和《中华 人民共和国植被图1:1000 000》(2007)记载, 在贺兰 山、祁连山、柴达木、阿尔泰山以及天山等干旱区 山地也有石生针茅草原的分布; 鉴于考察的时间和 地区有限, 在贺兰山、阿尔泰山以及柴达木地区未 发现有分布, 还有待更加全面的调查研究。

2)石生针茅草原作为荒漠草原的代表类型, 群 落数量特征低, 单位面积的物种饱和度不足 10 个, 旱生植物高达79\%, 生活型除了草本优势层片, 灌 木和半灌木也具有重要的作用, 这体现了对干旱少 雨生境的适应。出现在石生针茅草原中的种子植物 共计165种，与《中国植被》(1980)和《中华人民共 和国植被图1:1 000 000》(2007)记录到的74种相比, 极大地丰富了石生针茅草原的物种组成。

3)将石生针茅草原的生活型谱与典型草原(地 面芽植物 $65 \%$, 一年生植物 $15 \%$, 隐芽植物 $11 \%$, 地 上芽植物 $9 \%$ )和草甸草原(地面芽植物 $58 \%$, 一年生 植物 $7 \%$, 隐芽植物 $27 \%$, 地上芽植物 $6 \%$, 矮高位芽 植物 2\%)的生活型谱比较, 随着干旱程度增加, 耐 旱的半灌木和灌木类地上芽植物以及受雨水影响极 大的一年生植物比例明显增加, 而分布在水分较好 环境下的隐芽植物则逐步减少, 反映出常年干旱、 冬春严寒的气候条件(中国科学院内蒙古宁夏综合 考察队, 1985)。

4)石生针茅群系可划分为 6 个群从组和 29 个群 从, 每个群从组受到次优势种的生态特征和分布范 围的限制, 分布在不同区域内。与《中国植被》(1980) 和《中华人民共和国植被图1:1000 000》(2007)的6 个群丛相比, 丰富了石生针茅草原的多样性, 增加 了新类型。

基金项目 国家重点基础研究发展计划(973计划) (2014CB-138800)、国家科技支撑计划(2015BAC02B00) 和科技基础性工作专项(2015FY210200)。

致谢 感谢中国科学院大学资源与环境学院崔骁勇 教授提供青藏高原样方资料。

\section{参考文献}

Chen LZ, Sun H, Guo K (2014). Floristic and Vegetation Geography of China. Science Press, Beijing. (in Chinese) [陈 灵芝, 孙航, 郭柯 (2014). 中国植物区系和植被地理. 科学出版社, 北京.]

Inner Mongolia and Ningxia Scientific Expedition Group, Chinese Academic of Sciences (1985). Vegetation of Inner Mongolia. Science Press, Beijing. (in Chinese) [中国科学 院内蒙古宁夏综合考察队 (1985). 内蒙古植被. 科学出 版社, 北京.]

The Editorial Committee of Flora Intramongolica (1998). Flora Intramogolica. 2nd edn. Vol. 5. Inner Mongolia People’s Publishing House, Hohhot. (in Chinese) [内蒙古植物志编 辑委员会 (1998). 内蒙古植物志. 第二版. 第五卷. 内 蒙古人民出版社, 呼和浩特.]

The Editorial Committee of Flora of China, Chinese Academy of Sciences (2004). Flora Republicae Popularis Sinicae. Science Press, Beijing. (in Chinese) [中国科学院中国植物 志编辑委员会 (2004). 中国植物志. 科学出版社, 北京.]

The Editorial Committee of Vegetation Map of China, Chinese Academy of Sciences (2007). Vegetation Map of the People's Republic of China 1:1000000. Geological Publishing House, Beijing. (in Chinese) [中国科学院中国植被图编 辑委员会 (2007). 中华人民共和国植被图1:1000000. 地质出版社, 北京.]

The Editorial Committee of Vegetation of China (1980). Vegetation of China. Science Press, Beijing. (in Chinese) [中国 植被编辑委员会 (1980). 中国植被. 科学出版社, 北 京.]

Wu ZY, Raven PH, Hong DY (2013). Flora of China. Vol. 22: Poaceae. Science Press, Beijing; Missouri Botanical Garden, St. Louis. 197.

Yang Y, Guo K, Zhao LQ, Zhao HW, Qiao XG, Liu HM, Liu CC (2014). Community characteristics of Stipa roborowskyi in Xizang. Chinese Journal of Plant Ecology, 38, 635-639. (in Chinese) [杨瑶, 郭柯, 赵利清, 赵海卫, 乔 鲜果, 刘慧明, 刘长成 (2014). 西藏昆仑针茅草原的基 本特征. 植物生态学报, 38, 635-639.]

责任编委：王锁民 责任编辑：谢 巍

附录 中国石生针茅草原样方数据

Supplement Plot data of Stipa tianschanica var. klemenzii steppe in China http://www.plant-ecology.com/fileup/PDF/cjpe.2016.0053-D1.xls
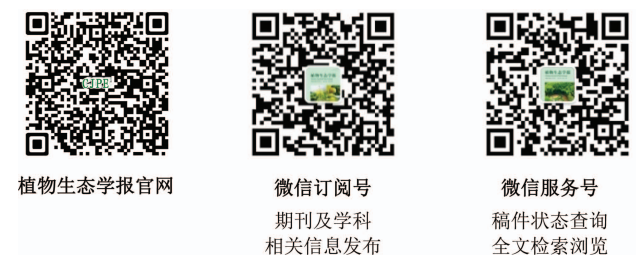

doi: 10.17521/cjpe.2016.0053 